\title{
M-Learning for children of 5-12 age groups in rural area of India
}

\author{
Amrapali Mhaisgawali \\ SNDT Women's University, \\ Usha Mittal Institute of Technology \\ Mumbai, India
}

\begin{abstract}
Internet has touched the urban and educated society in a big way. However the rural and less educated society is yet to enjoy the benefits. In India there are large number of non Internet Mobile users (NIMUs) -7.5 NIMUs for every internet users .It is hence essential that applications and products are designed with care and with usability in mind. Our own nation with a 1.2 billion population offers a business huge opportunity to develop socially relevant mobile applications for Rural India. Hence the primary objective of the paper is to reach to the NIMUs with mobile phone technologies and applications. The paper focus on implementing the M-learning application for NIMUs which display the animation of story and the voice will be played in the background .Beside the animation of story, the application has choices to display the story ,record the voice while reading the story ,videos of story and quizzes about the story, by keeping in mind the mental growth of child 5-12 age group.
\end{abstract}

Keywords- mobile learning, android, NIMUs, animation, Informal learning.

\section{INTRODUCTION}

According to the World Bank, "there are still precious few widespread examples of the use of [mobile] phones for education purposes inside or outside of classrooms in developing countries that have been well documented, and fewer still that have been evaluated with any sort of rigor"

[17]. The cellphone has been argued to be an appropriate device for educational delivery in the so-called developing world $[4,9]$. It is a low-power device that can be used in places without reliable electricity. Even though it is largely purchased for voice communications - which semi-literate users rely on for their social and economic needs - it is also able to run educational software that support visuals and voiceovers. Most of all, the cellphone is the fastest growing technology platform in the developing world. There are 2.2 billion mobile phones in developing regions like Africa and India, as compared to only 11 million desktops [6].

While cellphones can be deployed in schools in developing countries, the greatest opportunity is to facilitate informal learning in out-of-school environments so as to complement formal schooling. In underdeveloped regions, particularly rural areas, many schools are not only poorly equipped or lack highly-trained teachers. Worse, school attrition can be prevalent in underdeveloped regions. For instance, in rural India, about $43 \%$ of school-age children cannot attend school regularly because they have to work for the family in agricultural fields or households [3]. Mobile learning thus empowers poor children to balance their educational and income earning goals, by enabling them to learn anytime, anywhere, in places and times more convenient than school[1].

\section{RELATED WORK}

Koole [13] argues there is a tremendous scope for mobile learning and establishes a framework to assist practitioners in designing activities appropriate for mobile learning.Klopfer [12] adds that mobile learning games are not only engaging, but can also account for the user's context and environment to improve on the learning process. Mobile learning has been applied to the domains of nursing education [11], online communities [5, 6] and distance education $[8,14]$.Similarly, Jarkievich et al. [9] and Scanlon et al. [15] explore the usage of mobile phones in outside classroom settings, whereas Bell et al. [3] study the social interactions around cellphone-based games in everyday settings. However, all of the above studies are based in developed world settings. A major contribution of this paper is instead to explore the scope of mobile learning in poorer developing regions of the India.

\section{SYSTEM DESIGN}

\section{1) Mobile learning}

Mobile learning may be defined as handheld technologies, together with wireless and mobile phone networks, to facilitate, support, enhance and extend the reach of teaching and learning. Mobile learning (M-Learning) is one new learning mode by which an individual can use the mobile communication terminals to assist them to learn. Mobile learning is formed in the background of knowledge exploding, it syncretises the characteristics of modern education thought, computer network technology, mobile communications technology and multimedia technology. Mobile learning may also be defined as highly situated, personal, collaborative and long term; in other words, truly learner-centred learning. MLearning also provides instructors and education administrators with more flexible teaching and managing methods

\section{2) Purpose}


Our own nation with a 1.2 billion population offers a business huge opportunity to develop socially relevant mobile applications for Rural India . Hence, the primary objective of the proposed system would be to reach out to the non-Internet mobile users with mobile phone technologies and applications, with innovative research in Interaction Design addressing the various factors such as culture, language, user interfaces, modelling and software engineering, keeping diversity and scale in mind.

The work in understanding M-Learning would bring about a mass upheaval in contextually relevant, domain specific learning environment and is a step towards a well designed application or product development in this domain. Moreover, with the help of animations, it will help in better understanding and mental growth of child-5 Age group from distance villages and NGO's also.

\section{3) Description of the proposed system:}

The system consist of menus which will help the learner to learn about the options available.

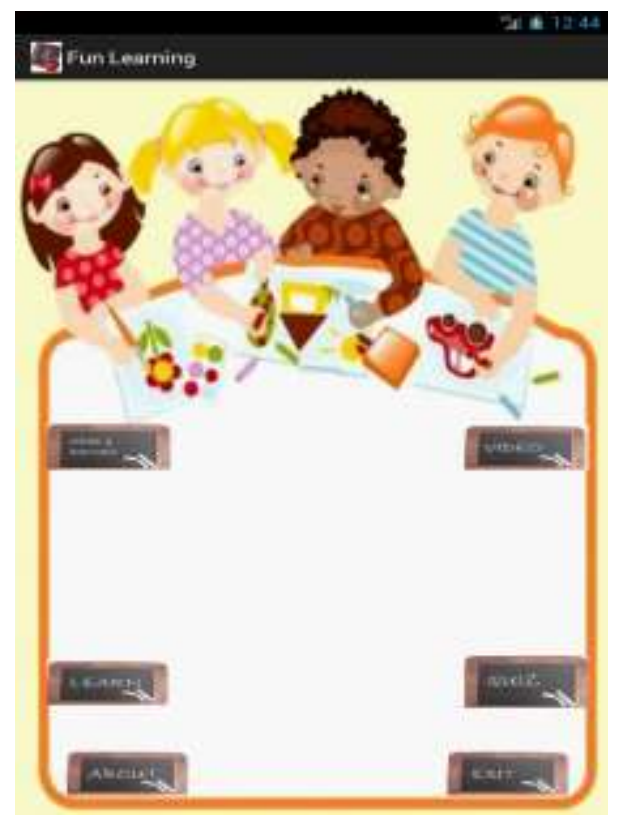

Fig. 1 Option Screen

Following are the options available

\subsection{1) Learn}

The option "learn" is for story animation, The animation is Frame animation using the class "AnimationDrawable" in Android. The frames are displayed after some microsecond one by one.

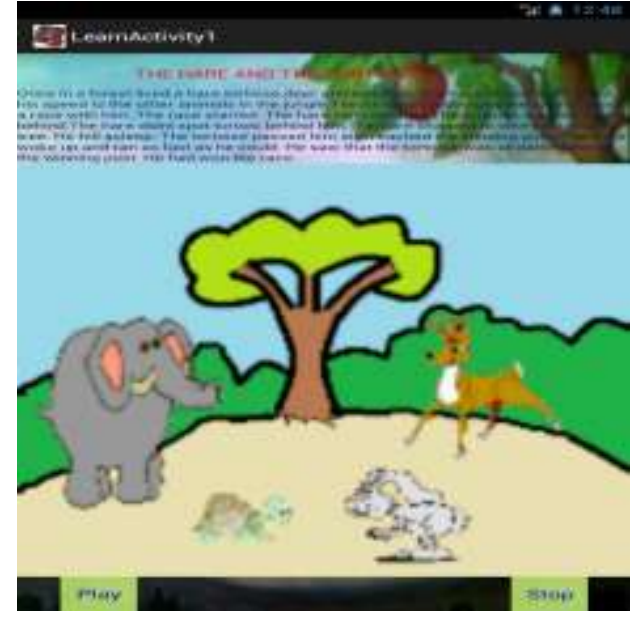

Fig 2 Animation of story

\subsection{2) Read and record}

The learner can read the story and record the story,so that she can listen the story later on.

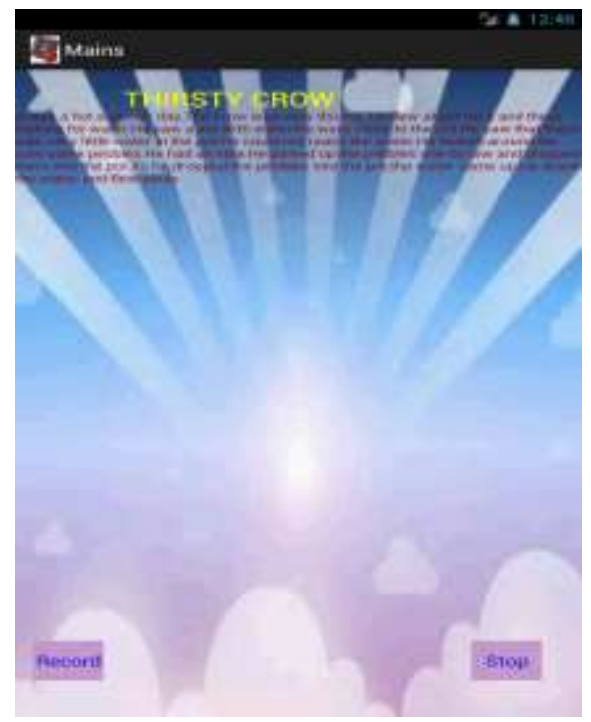

Fig. 3 Read and Record

\subsection{3) Video}

The learner can play the video which are available on mobile SD card. 


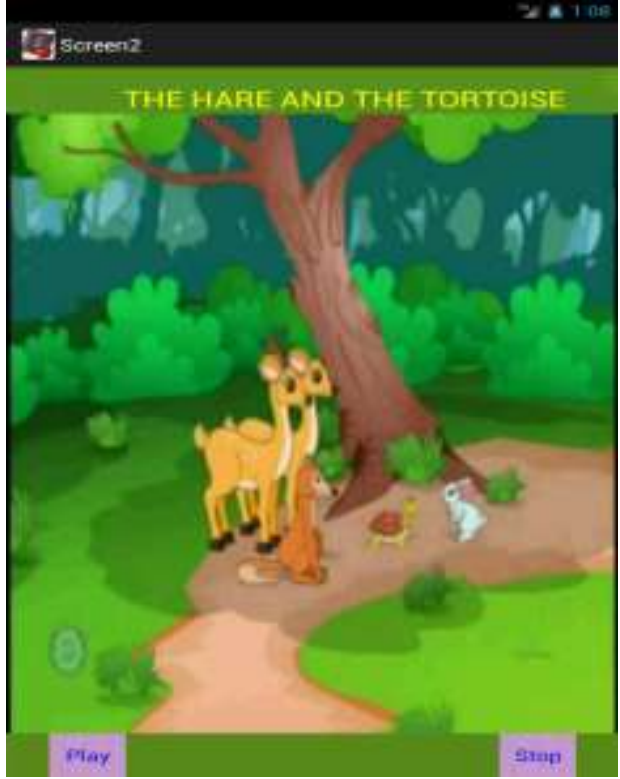

Fig. 4 Playing Video

\subsection{4) Quiz}

After listening the story the learner can give the answer of quiz . The questions are related to the story,which will help the leaner to memorize the story.

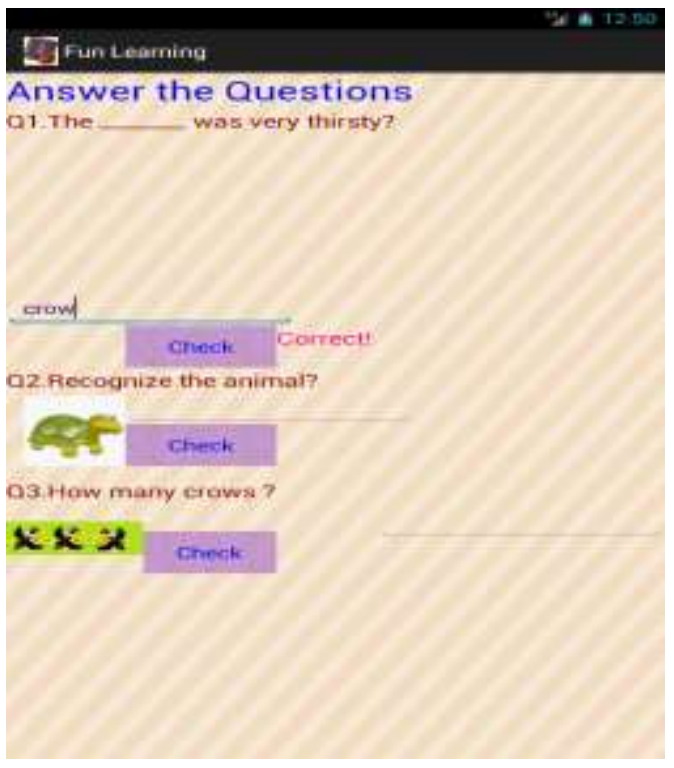

Fig. 5 Quizzes

\section{CONCLUSION}

The application is implemented which help to learn about the story using animation for the children in rural area of India. The primary objective of the proposed system is provide the standalone mobile learning application which facilitates the animation of story ,displaying of story ,recording of voice , videos of story and quizzes that test knowledge gained from the story. In future more stories can be added to enhance the learning experience.

\section{ACKNOWLEDGEMENT}

I would like to say thank to Supriya N., Palak Raina, Jyothsna $\mathrm{V}$. for their help to complete the project.I also thankful to $\mathrm{Mr}$ Vilas M. for supporting me for completion of the project.

\section{REFERENCES}

[1] An Exploratory Study of Unsupervised Mobile Learning in Rural India, Anuj Kumar1, Anuj Tewari2, Geeta Shroff1, Deepti Chittamuru3, Matthew Kam1 \& John Canny2 Human-Computer Interaction Institute, Carnegie Mellon University, USA Computer Science Division and Berkeley Institute of Design, University of California, Berkeley, USA School of Information, University of California, Berkeley, USA

[2] Azim Premji Foundation.The Social Context of Elementary Education in Rural India, 2004. http://www.azimpremjifoundation.org/downloads/TheSo cial ContextofElementaryEductaioninRuralIndia.pdf

[3] Bell, M., Chalmers, M., Barkhuus, L., Hall, M., Sherwood, S. Tennent, P., Brown, B., Rowland, D., and Benford, S. 2006. Interweaving mobile games with everyday life. In Proc. CHI '06, ACM Press, NY, USA.

[4] Brown. H. T., The role of m-learning in the future of elearning in Africa, 2003, ICDE World Conference.

[5] Cameron, L. Teaching languages to young learners. Cambridge University Press 2005

[6] Clough, G., Jones, A., McAndrew P., Scanlon, E. Informal learning evidence in online communities of mobile device enthusiasts. In Mobile Learning: Transforming the Delivery of Education and Training. Athabasca, AB: Athabasca University Press.

[7] CNN. Weapon against epidemics: cellphones http://edition.cnn.com/2009/TECH/science/06/16/cellpho nes.health.disease/H (Last accessed September 17, 2009).

[8] Gregson, J., Jordaan, D., Exploring the challenges and opportunities of m-learning within an international distance education programme. In M. Ally (Ed.), Mobile Learning:Transforming the Delivery of Education and Training. Athabasca, AB: Athabasca University Press.

[9] Jarkievich, P., Frankhammar, M., and Fernaeus, Y. In the hands of children: Exploring the use of mobile phone functionality in casual play settings. In Proc. Mobile HCI 2008, ACM Press, NY, USA.

[10] Kam, M., Kumar, A., Jain, S., Mathur, A., and Canny, J. Improving literacy in rural India: Cellphone games in an after-school program. In Proc. of IEEE/ACM Conference on ICTD'09.

[11] Kenny, R., Park, C., Kenny, J., Burton, P., Meiers, J. Using mobile learning to enhance the quality of nursing practice education. In M. Ally (Ed.), Mobile Learning: Transforming the Delivery of Education and Training. Athabasca Press. 
[12] Klopfer, E. Augmented Learning: Research and Design of Mobile Educational Games. The MIT Press, 2008.

[13] Koole, M. A Model for Framing Mobile Learning. In M. Ally(Ed.), Mobile learning: Transforming the delivery of education and training. Athabasca, AB: Athabasca University Press.

[14] Rekkedal, T., Dye, A. mobile distance learning with PDA's:Development and testing of pedagogical and system solutions supporting mobile distance learners. The International Review of Research in Open and Distance Learning, 2007.

[15] Scanlon, E., Jones, A., and Waycott, J. Mobile technologies:prospects for their use in learning in informal science settings. In Journal of Interactive Media in Education 2005/25. ISSN:1365-893X [jime.open.ac.uk/2005/25].

[16] WANG Feng-lin,LI Wang-xiu,LI Hua-xin.Quantitative analysis of domestic Articals on M-learning[j].Modern Education Technology .2008,18(12),62-66.

[17] World Bank. Surveying the use of mobile phones in educationworldwide.http://blogs.worldbank.org/edutech/ surveying-the-use-of-mobile-phones-in-educationworldwide (Last accessed September 14, 2009). 